\title{
Chapter 13 \\ Student Voice and Student Feedback: \\ How Critical Pragmatism Can Reframe \\ Research and Practice
}

\author{
Mari-Ana Jones and Valerie Hall
}

\begin{abstract}
This chapter recognises the diverse definitions and practices of student feedback; focussing on how student feedback can facilitate dialogue and thus contribute to the development of schools as democratic communities. Student feedback is thus positioned as a part of student voice, which has its roots in the United Nations Convention on the Rights of the Child (UNICEF, 1989). We question the ways in which schools elicit the views of students and how students' opinions are made use of, recognising the complexities arising from power relationships (Hart, 1992), the consumerisation of education (Whitty \& Wisby, 2007) and the pressures of accountability. Furthermore, we consider ways in which researchers can address difficulties in the research-practice relationship (Chapman and Ainscow, 2019) and facilitate co-creation of research. We propose the perspective of critical pragmatism as a means to acknowledge the complexities of practice, whilst also highlighting the importance of critical reflection and dialogue. Critical pragmatism could move us from a "deconstructive scepticism toward a reconstructive imagination" (Forester, 2012 , p. 6) in which schools and researchers collaborate to enable contextually rich practices of student feedback and student voice.
\end{abstract}

Keywords Student feedback $\cdot$ Student voice $\cdot$ Critical pragmatism $\cdot$ Dialogue $\cdot$ Reflection · Collaboration

\section{Introduction}

We recognise that there is a fundamental belief in the need for schools to provide safe environments in which students can speak, and for student feedback to be used to implement change (Defur \& Korinek, 2010). After all, "the first claim of the school is that of its pupils for whose welfare the school exists" (Stenhouse, 1983,

M.-A. Jones $(\varangle)$

Norwegian University of Science and Technology, Trondheim, Norway

e-mail: mari.a.jones@ntnu.no

V. Hall

University of Wolverhampton, Wolverhampton, UK 
p. 153). There is, however, much discussion about what we mean when we talk about "student feedback". We have chosen to accept the premise that student feedback can be defined as "the use of formal processes to gather information from students about their perceptions of teacher practices, teacher effectiveness and the quality of educational programmes" (Mandouit, 2018, p. 756).

However, the vocabulary used around student feedback has become increasingly diverse, with concepts holding different meanings for those involved (Forrest et al., 2007). The context within which such feedback is situated varies enormously: the cultural and environmental influences; the methods and practices used to elicit such feedback; policy and regulatory frameworks; the students and staff, and their relationships; and the purposes for which such feedback is sought. The overall intent may be about improvement, but the drivers come from a broad spectrum of need: from a performativity perspective that can demonstrate accountability and effectiveness (Verhaeghe et al., 2010); to opening up a "dialogue around teaching and learning in the classroom ... [that could give].... teachers insights into the unique challenges experienced by their students" (Mandouit, 2018, p. 755). In this form, student feedback can be identified as a form of student voice, with schools aiming to serve as democratic environments in which structures can be created that enable students, teachers and the broader school family, to have "meaningful involvement in decision-making processes" (Defur \& Korinek, 2010, p. 19) and for teachers' classroom practice to be improved (Bourke \& Loveridge, 2016; Mitra, 2008). Such opportunities for participation encourage the development of a student's sense of agency and self-worth; a sense of belonging and reflection on past, present and future relationships (Thompson, 2005).

Student voice and student feedback derived from different agendas. The expansion of interest in student voice can be traced to Article 12 in the United Nations Convention on the Rights of the Child (UNICEF, 1989), which states that children have the right to be heard. Student feedback - mainly developed in higher education institutions and intended as a quality assurance measure (Harvey, 2003) — has been used to gather views for a specific purpose. As such, their foundations are somewhat different, but there are important interconnections. At their best, they enable a collaborative dialogue and the development of consultation across all stakeholders (Nelson, 2015). At their worst, they become instrumentalist in demonstrating compliance (Charteris \& Smardon, 2019), or tokenistic in positioning students as consumers of education (Hall, 2020). We need to consider whether students are being engaged as "insiders" or "outsiders" (Forrest et al., 2007, p. 26): are they informing practice from within - through collaboration and agency; or is their purpose only to help fulfil the requirements of accountability frameworks?

Within this chapter, our focus is on student voice, but we acknowledge that this concept is also evidenced within student feedback and that there are many interlinking practices and connections between the two. We are thus interested in the ways in which researchers are in a position to support schools to critically explore how school communities espouse, enact and experience student voice (Hall, 2020). This chapter offers a critically pragmatic perspective that has the potential to enable student voice research to recognise the aspirations of student voice whilst not losing 
sight of the realities of school life. Schools can be enabled to reclaim student voice. They can value their own local knowledge and experiences and their own contexts, with the "thoughtful and serious consideration of student voice" (Keddie, 2015, p. 227) having the potential to yield considerable benefits. In doing so, opportunities emerge to develop contextually relevant practices that are: enriching for students and teachers alike (Bragg \& Manchester, 2012; Fleming, 2015); that take into account the diversity of concepts and contexts (Mandouit, 2018; Verhaeghe et al., 2010); and that consider the ways in which discourses interconnect and overlap within student feedback and student voice (Charteris \& Smardon, 2019). The discussion within this chapter, therefore, considers ways in which we as researchers may begin to facilitate "co-creation" of research; how we mediate and broker knowledge through "engaging in the identification and formulation of knowledge needs" (Wollscheid et al., 2019, p. 289).

\section{Situating the Chapter}

Within the broader context of student voice, and by association student feedback, there are many rich discussions taking place across an international arena. Central to much of this is the acknowledgement that there are difficulties in accommodating national policies and competing priorities, differences in school contexts, and views that exist on pedagogical approaches, as evidenced by research emerging from countries who are working on collaborative European projects (Bron et al., 2018; Holcar Brunauer, 2019). We need, therefore, to appreciate the constraints and challenges imposed on schools endeavouring to meet requirements, wherever they are situated. As demonstrated by research from New Zealand (Bourke \& Loveridge, 2016, p. 59) this also needs to recognise that sometimes the focus is on "what can be changed, and not what confronts practices especially if the student feedback is challenging". The discussion within this chapter thus aligns with themes across this wider debate and seeks to broaden perceptions of student voice research and practice, highlighting some of the key drivers that influence, and sometimes hinder, the development of a more critically pragmatic approach: a "philosophy for professionals" (Ulrich, 2007, p. 1112).

To make improvements in student outcomes we know that it makes sense to go straight to the source as students can not only share opinions about their classroom experiences, but also play a significant role in school improvement efforts. But how do we best involve students in school decisions that will shape their lives and the lives of their peers? (Mitra, 2008, p. 20).

There are, however, concerns about the methods used to elicit student feedbacksurveys, questionnaires, evaluation results. These relate not only to the validity of their construction and the questions asked, but also the ways in which any results are interpreted (Darwin, 2016), for "It is not just the collection of data that is important, but the value that is placed on student evaluations" (Blair \& Noel, 2014, p. 881). Institutions frequently find themselves operating between two conflicting objectives, 
"one which is focused on directives that accord success for meeting targets, and the other based on aspirations to enhance the community by allowing each student the possibility to be heard" (Shuttle, 2007, p. 33). A methodological quest for "authentic" student responses should be treated with caution (Spyrou, 2016), and Nelson (2015, p. 5) argues that a notion of authentic student voice "masks how power relations operate" in the production of student voice. Consideration needs to be given to who is assigning value and worth to such dialogue, and the emergent data, and how equal is the potential for all individuals to be involved (DeFur \& Korinek, 2010).

Hart (1992) recognised that there would be issues of power and participation when adults in such settings attempted to work in partnership with children. His much vaulted "ladder of participation"-moving from levels of non-engagement (manipulative and tokenistic) through to levels of engagement with evidence of growing consultation, agency and the development of shared power (with the potential for transformation) - has acted as a catalyst for much discussion in the arena (Fielding, 2001, 2011; Groundwater-Smith \& Mockler, 2016). Student voice has become a right and a "key aspect of youth agency" incorporating varied practices, but these require "careful, situated interpretation if we are to understand their meanings and effect" (Bragg \& Manchester, 2012, p. 143). This raises some fundamental questions for both students and teaching staff. Students may feel alienated through what might be seen as a "tokenistic" approach to student voice (Fielding, 2011) or consider themselves being positioned merely as "consumers of education" (Whitty \& Wisby, 2007, p. 303). Teaching staff may experience similar tensions in their understanding of the implications of student voice for teacher professionalism and whether it should be regarded as "an important element in establishing a 'collaborative' or 'democratic' professionalism, or a challenge to teachers' authority and cement an associated 'managerial' model of professionalism" (Whitty \& Wisby, 2007, p. 303). These discourses are linked, and even overlapping at times (Charteris \& Smardon, 2019), and consequently, schools have pressed on with various student voice initiatives that might demonstrate collaboration and engagement both for compliance purposes but also undoubtedly with good intent to engage learners in constructive dialogue. Due to the constraints of complex regulatory frameworks which require evidence of both compliance and learning, however, schools are rarely able to step back; to challenge and to seek ways in which student voice can be not only a "tool for change", but also a "tool for reflection" (Bourke \& Loveridge, 2016, p. 65).

So, the challenge from our perspective is how research can work more closely with teachers and empower them to incorporate student voice as "part of their own professional learning and development” (Bourke \& Loveridge, 2016, p. 66). If school leaders and teachers can become more "invested" in the creation and development of knowledge, they can participate further in the drive to identify and formulate those knowledge needs (Kauffman et al., 2017). This does not necessarily mean a call for more methodologies that facilitate the involvement of schools, or for greater engagement with action research, but rather an avoidance of a "linear dissemination from experts to practitioners" (Blackmore, 2007, p. 28). Our discussion, therefore, moves on to consider ways in which we might be able to "reframe" research within this context. 


\section{Reframing the Role of Student Voice Research}

Hargreaves (1999, p. 125) described a "division" between researchers and practitioners and Lester et al. (2002) raised the issue of how teachers and researchers might be expected to communicate when they obviously occupied different worlds. Researchers are frustrated with simplistic, mechanistic practices whilst teachers are subject to the supposed "moral and intellectual authority" of researchers who "derive their power" from criticising at a distance (Chapman \& Ainscow, 2019, p. 915). Blackmore (2007) described the failings of a linear view of the research-practice relationship in which knowledge is supposed to be passed down from academics to practitioners, pointing especially to the inaccessibility of the reporting of findings. This implies that language is the most significant barrier, however, Biesta et al. (2019) raise fundamental questions about perceptions of the relevance of research. Chapman and Ainscow (2019) criticise the ways in which knowledge is produced by research, advocating for an inclusive "messy social learning process" (p. 914) which addresses unequal power relationships between researchers and practitioners.

We contend that these issues are especially noticeable in student voice work. At times, as Mager and Nowak (2012, p. 50) suggest, student voice researchers have conducted "too little methodologically strong research". Fielding (2011, p. 10) argues that student voice research has not paid enough attention to theoretical frameworks, due to the "corrosive nature of market-led approaches". There are questions about the value of student voice research and its capacity to influence practice. Likewise, the emancipatory and empowerment traditions of student voice research contribute to difficulties in the enactment and experience of student voice (Hall, 2020). Whilst teachers were willing to engage with research, Bourke and Loveridge (2016) report that it was challenging for them to take account of findings which appeared to contradict their experiences and views. Harris (2010, p. 88) concurs, noting that teachers had varying responses to findings:

There were some teachers in each group who really wanted to be handed immediate ideas that they could take back to their classrooms. Others felt they came with considerable expertise and there was nothing new they did not already know. Still others were pleased to engage in reflective discussion and make their own links to classroom practice whilst being open to new ideas.

There are surprisingly few mandates for teachers to connect with educational research, despite the professionalisation of education, with teachers often seen as receiving knowledge from external sources, rather than being part of creating it (Wollscheid et al., 2019). An argument further supported by Harris (2010), who suggests that teachers are expected to receive and reproduce knowledge. Our intention, therefore, is to propose a reframing of research and the roles of researchers and practitioners, which involves a "reconstruction of relations" (Hargreaves, 1999, p. 136) in which teachers are "at the heart" (ibid.). To achieve these aims we need a "brokering" system (Wollscheid et al., 2019, p. 270) in which knowledge moves fluidly and dynamically between research and practice. For student voice research, 
these suggestions would support the construction of a dialogue which is more in keeping with the democratic, inclusive and transformational traditions of the field (Fielding, 2011). In this way, the concerns raised about how research might "reach" the "practice of education ... [moving the focus and so] ... changing the location of research and the identity of the researcher" (Biesta et al., 2019, p. 2) lead us to our next consideration: where, and how, such a shift might be enabled.

\section{Critical Pragmatism as a Way Forward}

So, having established the tensions, constraints — and possibilities, how might we find a way forward? What has emerged from the discussion is the need to reach "beyond the confines of technical philosophy" (Dewey, 1949, p. xiv) towards a more critical approach. Such a perspective has the potential to help "bridge" the gap and facilitate discussion between research and practice and to have progressive adjustments made "in light of collective deliberation grounded in the experience of every member of society" (Curren, 2010, p. 494). Before considering its relevance and how it might be applied to student voice research and practice, it is necessary to first define critical pragmatism.

Critical pragmatism incorporates both pragmatism and critical theory. Dewey (1925) identifies Peirce (1839-1914) as the originator of pragmatism, having been inspired by Kant's 1785 distinction between the practical and the pragmatic. Dewey (1925) explains that Peirce was interested in how concepts could be made clear, which according to Peirce, could only be achieved by their application to human experience. Dewey (1925) elaborates, arguing that action is the intermediary through which concepts gain meaning. Furthermore, because actions can be different, meanings can be different. Biesta (2006, p. 30) interprets Dewey's thinking thus; "it is because people share in a common activity that their ideas and emotions are transformed as a result of the activity in which they participate". When applied to student voice, this understanding of pragmatism can help to explain variations in understandings and practices between schools, as well as divisions between the conceptualisation of student voice in theory and policy and how it is practised. Put simply, the concept of student voice is actioned in many ways, leading to multiple experiences and understandings. The critical aspect is crucial; encouraging reflective practice and drawing attention to power issues. As Feinberg (2015, p. 151) explains "the distinctive task of critical pragmatism is to bring competing norms to the surface, to show how they impede experience and to encourage the formation of new ways."

At the start of this chapter, we began to explore some of the tensions that exist between student voice used as an accountability measure (Verhaeghe et al., 2010), and student voice being part of schools' democratic processes (Bourke \& Loveridge, 2016; Defur \& Korinek, 2010; Mitra, 2008). We witness teachers and schools endeavouring to meet external accountability requirements connected with education's "marketisation and the development of a consumer culture" (Murphy \& Skillen, 
2013, p. 84). Keddie (2015, p. 226) describes teachers having "a sense of powerlessness and high levels of uncertainty". Teachers express concerns about the erosion of their "ability to complete what they consider core professional tasks - dealing with the issues and concerns of pupils" (Murphy \& Skillen, 2013, p. 89). In this climate, there is a danger that the potential of student voice as a reflective tool can be forgotten. For schools, critical pragmatism as a lens can be useful as a means of acknowledging the demands of accountability, whilst also encouraging critical reflection. A critical pragmatist perspective suggests compromise rather than an either-or perspective; student voice need not be either for accountability or for democracy. Rather, by providing "fertile ground on which such ideas can be questioned, refined or even transformed" (Murphy \& Skillen, 2013, p. 95), it enables schools to critically reflect on their practices of student voice. For example, the ways in which they are collecting the views of students and what they are doing with the data.

For student voice researchers, critical pragmatism encourages an acknowledgement of the realities of the complex network of demands on schools and the need for action, as well as a recognition of the importance of local knowledge and understanding in the practice of student voice. Taking a critical pragmatist stance mitigates against researchers becoming overly critical of student voice practices, instead highlighting the importance of examining contextualised practice. The potential now exists for research and practitioners to recognise and acknowledge that it is no longer enough for the role of research to be rooted in production of "evidence-based practice" or "evidence-informed teaching": the "what works" as discussed by Biesta et al. (2019). Rather, researchers can seek to co-construct research knowledge that is "geared towards producing useful knowledge which is able to answer the questions practice ask ... [whilst also acknowledging] .... What does it work for?" (Biesta et al., 2019, p. 2).

It is, therefore, time to reframe our perceptions and perspectives so that rather than "determining practice" we grasp the potential for research to 'inform practice', with teachers viewed not as "recipients of research and reproducers of knowledge", but rather as "producers and interrogators of research and builders of knowledge" (Harris, 2010, p. 83) in their professional capacities. A critical pragmatist orientation could thus have the potential to foster mediation, respecting the perspectives of all those involved, and — crucially — enabling each to learn "from, and about, each other, so that they can work to invent creative new options for action, [and] work to produce pragmatic outcomes serving their values and interests, as well" (Forester, 2012, p. 13). Critical pragmatism can enable a dialogue between researchers and schools - mutual recognition of each other's standpoints and encourage learning from each other.

\section{Conclusion}

Although the focus of our chapter is student voice, we highlight interconnections with student feedback, appreciating that in spite of their different foundations and agendas, the two concepts have much in common. We have considered the diversity of concepts 
and contexts (Mandouit, 2018; Verhaeghe et al., 2010), acknowledging that there are discourses that interlink and overlap (Charteris \& Smardon, 2019). The capacity for collaborative dialogue and consultation across stakeholders (Nelson, 2015) on the one hand; but also, the potential to be instrumentalist, tokenistic and compliance driven (Charteris \& Smardon, 2019) on the other. Our aim in this discussion, therefore, is for student feedback and student voice research to be understood as "bounded in both the context and the culture of specific settings ... [that make it] ... complex, challenging and contradictory" (Fleming, 2015, p. 224). In doing so, we broaden the debate about the ways in which both student feedback and student voice are "espoused, enacted and experienced" (Hall, 2020, p. 125) by researchers and in schools.

Situated amidst complex regulatory frameworks, schools at times operate between conflicting objectives. It can, therefore, be difficult to see ways in which student feedback and student voice research can navigate competing priorities, institutional contexts, and pedagogical beliefs (Bourke \& Loveridge, 2016; Bron et al., 2018; Holcar Brunauer, 2019). Researchers have an important role. Instead of positioning ourselves as remote experts, disseminating our findings and criticising practice from afar, we are suggesting the development of a "close-to-practice" approach (Wyse et al., 2020, p. 20). Researchers should seek collaboration with practitioners, thus encouraging an iterative process of research and application that includes "reflections on practice, research, and context" (ibid.). If there is to be change, then it needs to be through mediation of the knowledge (Wollscheid et al., 2019); and that knowledge has to have been co-constructed. A critically pragmatic perspective for both researchers and schools could facilitate the development of contextually rich practice(s) - recognising the constraints that schools operate within, whilst taking the strengths of pragmatic thought, valuing local knowledge and experiences (Keddie, 2015) and also contributing a critical lens.

To support these aspirations, we propose the following:

- Developing a philosophy of enquiry and research amongst teachers;

- Considering the initial, and continuing, professional development needed for teachers to engage meaningfully in classroom research-perhaps a "toolkit" for teachers that can help to bridge the gap;

- Building a culture that ensures research is done with, not "on", teachers, students and the institution;

- Ensuring consensus about the educational implications of any activity and research undertaken; and

- Working collaboratively to identify and promote those forms of interaction that have the most beneficial educational outcomes.

We suggest that critical pragmatism could provide a means through which to work towards these aims, enabling us to "rethink the complexities of deliberative processes" (Forester, 2012, p. 6); for researchers to start from where schools are and at the same time enable schools to critically examine their practice. Our premise, therefore, is that critical pragmatism could move us from a "deconstructive scepticism toward a reconstructive imagination" (Forester, 2012, p. 6) where there are 
possibilities for joint gain; and for multi-directional gain that may satisfy the multiple and diverse needs of all.

\section{References}

Biesta, G. (2006). "Of all affairs, communication is the most wonderful": The communicative turn in Dewey's Democracy and Education. In D. T. Hansen (Ed.), John Dewey and our educational prospect: A critical engagement with Dewey's Democracy and Education (pp. 23-38). State University of New York Press. https://doi.org/10.1111/j.1748-5959.2008.00161.x.

Biesta, G., Filippakou, O., Wainwright, E., \& Aldridge, D. (2019). Why educational research should not just solve problems but should cause them as well. British Educational Research Journal, 45(1), 1-4. https://doi.org/10.1002/berj.3509.

Blackmore, J. (2007). How is educational research "being framed"? In B. Somekh \& T. Schwandt (Eds.), Knowledge production (pp. 24-41). Routledge. https://doi.org/10.4324/9780203609156.

Blair, E., \& Noel, K. V. (2014). Improving higher education practice through student evaluation systems: Is the student voice being heard? Assessment and Evaluation in Higher Education, 39(7), 879-894. https://doi.org/10.1080/02602938.2013.875984.

Bourke, R., \& Loveridge, J. (2016). Beyond the official language of learning: Teachers engaging with student voice research. Teaching and Teacher Education, 57, 59-66. https://doi.org/10.1016/ j.tate.2016.03.008.

Bragg, S., \& Manchester, H. (2012). Pedagogies of student voice. Revista de Educación, 359, 143-163. https://doi.org/10.4438/1988-592X-RE-2012-359-200.

Bron, J., Emerson, N., \& Kákonyi, L. (2018). Diverse student voice approaches across Europe. European Journal of Education, 53(3), 1-28. https://doi.org/10.1111/ejed.12285.

Chapman, C., \& Ainscow, M. (2019). Using research to promote equity within education systems: Possibilities and barriers. British Educational Research Journal, 45(5), 899-917. https://doi.org/ 10.1002/berj.3544.

Charteris, J., \& Smardon, D. (2019). The politics of student voice: Unravelling the multiple discourses articulated in schools. Cambridge Journal of Education, 49(1), 93-110. https://doi. org/10.1080/0305764X.2018.1444144.

Curren, R. (2010). Pragmatist philosophy of education. In H. Siegel (Ed.), The Oxford handbook of philosophy of education (pp. 489-507). Oxford University Press. https://doi.org/10.1093/oxf ordhb/9780195312881.003.0027.

Darwin S. (2016). Student evaluation in higher education: Reconceptualising the student voice. Springer International Publishing. https://doi.org/10.1007/978-3-319-41893-3_2.

DeFur, S., \& Korinek, L. (2010). Listening to student voices. The Clearing House: A Journal of Educational Strategies, Issues and Ideas, 83(1), 15-19. https://doi.org/10.1080/000986509032 67677.

Dewey, J. (1925). The essential dewey. Volume 1: Pragmatism, education, democracy (L. A. Hickman \& T. M. Alexander, Eds.) (1998). Indiana University Press.

Dewey, J. (1949). Foreword. In P. Wiener (Ed.), Evolution and the founders of pragmatism (pp. xiii-xiv). Harvard University Press. https://doi.org/10.9783/9781512808483.

Feinberg, W. (2015). Critical pragmatism and the appropriation of ethnography by philosophy of education. Studies in Philosophy and Education, 34, 149-157. https://doi.org/10.1007/s11217014-9415-6.

Fielding, M. (2001). Students as radical agents of change. Journal of Educational Change, 2(2), 123-141. https://doi.org/10.1023/A:1017949213447.

Fielding, M. (2011). Student voice and the possibility of radical democratic education. In G. Czerniawski \& W. Kidd (Eds.), The student voice handbook (pp. 3-17). Bingley. 
Fleming, D. (2015). Student voice: An emerging discourse in Irish Education Policy. International Electronic Journal of Elementary Education, 8(2), 223-242. https://www.iejee.com/index.php/ IEJEE/article/view/110. Accessed 6 Aug 2020.

Forester, J. (2012). On the theory and practice of critical pragmatism: Deliberative practice and creative negotiations. Planning Theory, 12(1), 5-22. https://doi.org/10.1177/1473095212448750.

Forrest, C., Lawton, J., Adams, A., Louth, T., \& Swain, I. (2007). The impact of learner voice on quality improvement. In D. Collinson (Ed.), Researching leadership in the learning and skills sector: By the sector, on the sector, for the sector: Volume 4 (pp. 13-29). https://www.researchg ate.net/publication/280092665_Leadership_and_the_Learner_Voice. Accessed 6 Aug 2020.

Groundwater-Smith, S., \& Mockler, N. (2016). From data source to co-researchers? Tracing the shift from 'student voice' to student-teacher partnerships in educational action research. Educational Action Research, 24, 159-176. https://doi.org/10.1080/09650792.2015.1053507.

Hall, V. J. (2020). Reclaiming student voice(s): Constituted through process or embedded in practice? Cambridge Journal of Education, 50(1), 125-144. https://doi.org/10.1080/0305764X.2019. 1652247.

Hargreaves, D. H. (1999). The knowledge-creating school. British Journal of Educational Studies, 47(2), 122-144. https://doi.org/10.1111/1467-8527.00107.

Harris, P. (2010). Mediating relationships across research, policy, and practice in teacher education. Studying Teacher Education, 6(1), 75-93. https://doi.org/10.1080/17425961003669334.

Hart, R. A. (1992). Children's participation: From tokenism to citizenship (Innocenti Essays No. 4). UNICEF International Child Development Centre. https://1lk.media.mit.edu/courses/mas714/ fall03/unicef.pdf. Accessed 6 Aug 2020.

Harvey, L. (2003). Student feedback [1]. Quality in Higher Education, 9(1), 3-20. https://doi.org/ $10.1080 / 13538320308164$.

Holcar Brunauer, A. (Ed.) (2019). Student voice in education. CIDREE Yearbook 2019. National Education Institute Slovenia. https://www.zrss.si/digitalnaknjiznica/CIDREE_Yearbook_2019. pdf. Accessed 3 May 2020.

Kauffman, J. M., Hallahan, D. P., \& Pullen, P. C. (Eds.). (2017). Handbook of special education (2nd ed.). Routledge. https://doi.org/10.4324/9781315517698.

Keddie, A. (2015). Student voice and teacher accountability: Possibilities and problematics. Pedagogy, Culture and Society, 23(2), 225-244. https://doi.org/10.1080/14681366.2014.977806.

Lester, F. K., Wiliam, D., \& Lester, F. K. Jr. (2002). On the purpose of mathematics education research: Making productive contributions to policy and practice. In L. D. English, M. B. Bussi, G. A. Jones, R. A. Lesh, \& D. Tirosh (Eds.), Handbook of international research in mathematics education (pp. 489-506). Lawrence Erlbaum Associates.

Mager, U., \& Nowak, P. (2012). Effects of student participation in decision making at school: A systematic review and synthesis of empirical research. Educational Research Review, 7(1), 38-61. https://doi.org/10.1016/j.edurev.2011.11.001.

Mandouit, L. (2018). Using student feedback to improve teaching. Educational Action Research, 26(5), 755-769. https://doi.org/10.1080/09650792.2018.1426470.

Mitra, D. (2008). Amplifying student voice. Educational Leadership, 66(3), 20-25. http://www. ascd.org/publications/educational-leadership/nov08/vol66/num03/Amplifying-Student-Voice. aspx. Accessed 6 Aug 2020.

Murphy, M., \& Skillen, P. (2013). The politics of school regulation: Using Habermas to research educational accountability. In M. Murphy (Ed.), Social theory and education research, understanding Foucault, Habermas, Bourdieu and Derrida (pp. 84-97). Routledge.

Nelson, E. (2015). Student voice as regimes of truth: Troubling authenticity. Middle Grades Review, 1(2) Article 3. https://pdfs.semanticscholar.org/d32f/bbe6415fa11bfd4319639b5c6c0 928a55d0e.pdf. Accessed 6 Aug 2020.

Shuttle, J. (2007). Learners involvement in decision making. In D. Collinson (Ed.), Researching leadership in the learning and skills sector: By the sector, on the sector, for the sector: Volume 4 (pp. 30-48). https://www.researchgate.net/publication/280092665_Leadership_and_the_Lea rner_Voice. Accessed 6 Aug 2020. 
Spyrou, S. (2016). Researching children's silences: Exploring the fullness of voice in childhood research. Childhood, 23(1), 7-21. https://doi.org/10.1177/0907568215571618.

Stenhouse, L. (1983). Authority, education and emancipation. Heinemann Educational.

Thompson, C. (2005). The non-transparency of the self and the ethical value of Bildung. Journal of Philosophy of Education, 39(3), 519-533. https://doi.org/10.1111/j.1467-9752.2005.00451.x.

Ulrich, W. (2007). Philosophy for professionals: Towards critical pragmatism. The Journal of the Operational Research Society, 58(8), 1109-1113. https://www.jstor.org/stable/25681907. Accessed 6 Aug 2020.

UNICEF. (1989). The United Nations Convention on the Rights of the Child. London. https:// downloads.unicef.org.uk/wp-content/uploads/2010/05/UNCRC_united_nations_convention_ on_the_rights_of_the_child.pdf. Accessed 6 Aug 2020.

Verhaeghe, G., Vanhoof, J., Valcke, M., \& Van Petegem, P. (2010). Using school performance feedback: Perceptions of primary school principals. School Effectiveness and School Improvement, 21(2), 167-188. https://doi.org/10.1080/09243450903396005.

Whitty, G., \& Wisby, E. (2007). Whose voice? An exploration of the current policy interest in pupil involvement in school decision-making. International Studies in Sociology of Education, 17(3), 303-319. https://doi.org/10.1080/09620210701543957.

Wollscheid, S., Stensaker, B., \& Bugge, M. (2019). Evidence-informed policy and practice in the field of education: The dilemmas related to organizational design. European Education, 51, 270-290. https://doi.org/10.1080/10564934.2019.1619465.

Wyse, D., Brown, C., Oliver, S., \& Poblete, X. (2020). The BERA close-to-practice research project: Research report. British Educational Research Association. https://www.bera.ac.uk/publication/ bera-statement-on-close-to-practice-research. Accessed 6 Aug 2020.

Mari-Ana Jones After working as a teacher and school leader for over fifteen years in the UK and Norway, Mari-Ana Jones took up a research position (Ph.D.) at the Norwegian University of Science and Technology (NTNU). Her research interests include student voice and school improvement, with a particular focus on the role of school leadership. Mari-Ana leads the Master's in Educational Leadership at NTNU and is an Academic Supervisor on the National Program for School Leaders in Norway. She is also a consultant on school improvement and leadership in several school districts in Norway.

Valerie Hall has spent almost thirty years in Further and Higher Education in the UK in senior leadership positions, teaching and supervising across Masters and Doctoral level programmes, and in the last decade having a strategic lead in Initial Teacher Education (ITE) in the postcompulsory sector. Her practice and research focus is centred on student voice, and explores individual perspectives, including self-efficacy, self-categorization, and social identities. Valerie currently holds the position of Honorary Research Fellow at the Education Observatory, University of Wolverhampton. She is also an External Academic Advisor to another ITE provider in the UK. 
Open Access This chapter is licensed under the terms of the Creative Commons Attribution 4.0 International License (http://creativecommons.org/licenses/by/4.0/), which permits use, sharing, adaptation, distribution and reproduction in any medium or format, as long as you give appropriate credit to the original author(s) and the source, provide a link to the Creative Commons license and indicate if changes were made.

The images or other third party material in this chapter are included in the chapter's Creative Commons license, unless indicated otherwise in a credit line to the material. If material is not included in the chapter's Creative Commons license and your intended use is not permitted by statutory regulation or exceeds the permitted use, you will need to obtain permission directly from the copyright holder.

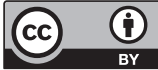

